\title{
Responses to Dynamic Head-and-Body Tilts are Enhanced in Parkinson's Disease
}

\author{
Nicole Paquet and Christina W.Y. Hui-Chan
}

\begin{abstract}
Background: Previous studies demonstrated that destabilizing responses to slow perturbations were enhanced in patients with Parkinson's disease (PD). Our objectives were to investigate the influence of PD on responses to faster whole head-andbody tilts in the standing position, and to establish whether any modification of tilt-evoked responses in PD patients was related to possible changes in the modulation of soleus (SO) H-reflex. Methods: Ten PD patients and 10 age-matched normal subjects assumed a standing position on an L-shaped tilting apparatus. Their head and shoulders were firmly attached to the back support of the apparatus, while their feet were fixated to the standing platform. With their vision occluded, the subject's whole head-and-body was suddenly tilted forward to $20^{\circ}$, at a peak head acceleration of $0.7 \mathrm{~g} \pm 0.1 \mathrm{~g}$. Tilt-evoked responses were recorded from the lower limb muscles bilaterally. In addition, $40 \mathrm{H}$-reflexes were elicited in the SO muscle at 30-190 ms intervals after the onset of head acceleration. The M response amplitude was kept within $\pm 15 \%$ of its control value. Results: PD patients demonstrated an abnormally high responsiveness to whole head-and-body tilts in comparison with age-matched normal subjects. This was shown by the significantly larger proportion of PD patients manifesting responses in the SO, biceps femoris and vastus lateralis muscles ( $<<0.05$ ), as well as their significantly larger SO response area $(413 \%$; $<<0.01)$. In contrast, the amplitude of the SO H-reflex was significantly increased by only $14 \%$ ( $<<0.05$ ) in these patients, and only at 30-70 ms after head acceleration onset. Conclusions: The overexcitable tilt-evoked responses of PD patients could originate from a reduced ability to suppress responses when the body is supported. This enhanced excitability of tiltevoked responses was probably not due to motoneuronal hyperexcitability or decreased presynaptic inhibition of the group Ia terminals involved in the mainly monosynaptic H-reflex pathway. Thus, we hypothesize that the control of spinal interneurons involved in the tilt-evoked responses may be defective in PD.
\end{abstract}

RÉSUMÉ: Les réponses aux bascules dynamiques de l'ensemble tête-corps sont augmentées dans la maladie de Parkinson. But: Des études antérieures ont démontré que les réponses déstabilisatrices à des perturbations lentes étaient augmentées chez les patients atteints de la maladie de Parkinson (MP). Nos objectifs étaient d'étudier l'influence de la MP sur les réponses à des basules plus rapides de l'ensemble tête-corps, et d'établir si des modifications des réponses à la bascule étaient reliées à des changements possibles de la modulation du réflexe-H du muscle soléaire (SO). Méthode: Dix patients atteints de la MP et 10 sujets normaux appariés pour l'âge étaient placés debout sur une structure basculante en forme de "L". Leur tête et leurs épaules étaient fermement attachées au support dorsal de la structure, et leurs pieds à la plate-forme de support. L'ensemble tête-corps était soudainement basculé vers l'avant de $20^{\circ}$, en l'absence de vision, à un pic moyen d'accélération de la tête de $0.7 \mathrm{~g} \pm 0.1 \mathrm{~g}$. Les réponses à la bascule étaient enregistrées au niveau des muscles des jambes des deux côtés. De plus, 40 réflexes-H ont été élicités dans le muscle SO à intervalles 30 de 190 ms après le début de l'accélération de la tête. L'amplitude de la réponse $M$ était gardée à $\pm 15 \%$ de la valeur contrôle. Résultats: Les patients atteints de la MP ont démontré une réactivité anormalement élévée aux bascules en comparaison avec les sujets âgés normaux. Une proportion significativement plus grande de patients atteints de la MP ont manifesté des réponses à la bascule dans les muscles SO, biceps fémoral et vaste externe (p<0.05), et l'aire de la réponse dans leur muscle SO était significativement plus grande (413\%; $\mathrm{p}<0.01)$. Au contraire, l'amplitude du réflexe-H des patients atteints de la MP n'était significativement augmentée que de $14 \%(\mathrm{p}<0.05)$, et seulement entre 30 et $70 \mathrm{~ms}$ après le début de l'accélération de la tête. Conclusions: L'hyperexcitabilité des réponses à la bascule des patients atteints de la MP pourrait provenir d'une capacité réduite à atténuer les réponses lorsque le corps est supporté. Cette excitabilité augmentée ne semblait pas due à une hyperexcitabilité des motoneurones ou une diminution de l'inhibition présynaptique des terminaisons du groupe Ia impliquées dans la voie principalement monosynaptique du réflèxe-H. Ainsi, nous posons l'hypothèse que le contrôle des interneurones spinaux impliqués dans les réponses à la bascule puisse être défectueux dans la MP.

Can. J. Neurol. Sci. 1997; 24: 44-52

One of the four cardinal signs of Parkinson's disease (PD) is the impairment of postural reflexes. ${ }^{1}$ As a result, an estimated $55 \%$ proportion of PD patients manifest postural instability and gait disorders. ${ }^{2}$ For instance, PD patients show more loss of balance than age-matched normal subjects, when standing blindfolded on a platform that moves in parallel to their sway. ${ }^{3}$ They also demonstrate smaller forward-backward body sway while standing, in comparison with age-matched normal subjects. ${ }^{4}$ Furthermore, the maximum inclined antero-posterior position they can maintain for 1 minute is significantly less than in similarly aged normal subjects. ${ }^{5}$ These results indicate that the limits within which PD patients maintain stable standing position are narrower in comparison with age-matched normal subjects.

In addition to their loss of static postural stability, patients with PD have demonstrated abnormally enhanced responses to

From the School of Physical and Occupational Therapy and Physiology Department, Faculty of Medicine, McGill University, Montreal.

RECEIVED JANUARY 24, 1996. ACCEPTED IN FINAL FORM JULY 9, 1996.

C.W.Y.H.-C. is currently on leave from the Department of Rehabilitation Sciences, The Hong Kong Polytechnic University, Hong Kong.

Reprint requests to: Nicole Paquet, Ph.D., Aerospace Medical Research Unit, McGill University, 3655 Drummond, Room 1220, Montreal, Quebec, Canada H3G 1 Y6 
dynamic perturbations in standing. For instance, they showed an increase in the medium latency responses of the gastrocnemius muscle stretched by sudden toe-up rotation of the standing platform. ${ }^{6-8}$ These responses were considered destabilizing because they contributed to a backward body sway following the platform rotation. Abnormally large responses were also found in the tibialis anterior (TA) muscle of PD patients evoked by backward translation of the standing platform. ${ }^{4,8}$ These responses were also considered destabilizing because they increased the forward sway produced by the backward translation. Taken together, these results indicate that the excitability of non-functional balance responses could be increased in PD.

We recently developed a new experimental paradigm to characterize tilting disorders in human subjects. Blindfolded subjects stood on an L-shaped tilting apparatus with their head and shoulders firmly attached to the back support of the apparatus and their feet fixed to the standing platform. As the apparatus was suddenly displaced forward by $20^{\circ}$, the subjects' head-and-body was tilted as a whole with minimum neck, body and ankle movements. Such whole head-and-body tilts were achieved with a spring-activated tilting apparatus and proper subject fixation, which we had previously described in a methodological paper. ${ }^{9}$ This paradigm has been proven to provide reproducible magnitude of linear head acceleration from trial to trial, and from subject to subject.

These forward tilts were found to evoke electromyographic (EMG) responses in the lower limb muscles of young normal subjects. Interestingly, the frequency of occurrence of tiltevoked responses increased progressively with an increasing intensity of head acceleration, ${ }^{10}$ which suggested that tilt-evoked responses could be modified by vestibular stimulation. Since parkinsonian postural instability was associated with abnormal responses to caloric stimulation of the vestibular apparatus, ${ }^{11}$ a question arose as to whether lower limb responses to forward whole head-and-body tilts were modified in PD. The first objective of this study is to characterize the tilt-evoked responses in a group of PD patients by comparing the findings with those of age-matched normal subjects.
Another application of our paradigm is to study the modulation of segmental reflexes during whole head-and-body tilts. An investigation of soleus ( $\mathrm{SO}$ ) $\mathrm{H}$-reflex modulation during tilts in PD patients could provide insight into possible mechanisms underlying their tilting disorders. In particular, it should reveal whether possible effects of PD on the tilt-evoked responses is accompanied by similar changes in the excitability of the predominantly monosynaptic stretch reflex. Therefore, the second objective of this study is to determine whether possible modifications of tilt-evoked responses in the SO muscle of PD patients can be related to similar changes in SO H-reflex modulation during forward head-and-body tilts.

\section{METHODS}

\section{Subjects}

We examined ten healthy subjects ( 1 man and 9 women) aged 51 to 70 years $($ mean $=63 \pm$ S.D. 7 years). They were volunteer participants with no neurological or neuromuscular disorders.

Ten patients with idiopathic PD ( 7 men and 3 women) in stage 3 of the disease, ${ }^{12}$ and aged 45 to 77 years (mean $=66 \pm 10$ years), participated in the study (Table 1). All patients were ambulatory, but reported balance difficulties such as falls, loss of balance, or feeling of instability and fear of falling. All subjects gave written informed consent approved by a Local Ethics Committee.

\section{Experimental Procedure}

Subjects were tested in an experimental session lasting 2-2.5 hours. PD patients were on their usual medication during the experiment. This procedure was done to ensure safe experimental conditions, and to maximize the patient's tolerance to the testing procedure. We hypothesized that possible tilting disorders would not be masked by the anti-parkinsonian medication, because clinical observation showed that postural impairments are resistant to dopamine replacement therapy. ${ }^{13}$ In addition, antiparkinsonian medication was found to be ineffective in

\begin{tabular}{|c|c|c|c|c|c|c|}
\hline Pt \# & Age (yrs) & Gender & Duration of PD (yrs) & Antiparkinsonian medication & \# Falls in last 6 mos $\dagger$ & Presence of retropulsion $\diamond$ \\
\hline 1 & 66 & $\mathbf{M}$ & 13 & Sinemet, Symmetrel, Eldepryl & 1 & absent reaction \\
\hline 3 & 73 & $\mathbf{M}$ & 7 & Sinemet, Eldepryl & 0 & no \\
\hline 4 & 64 & M & 3 & Sinemet-CR, Symmetrel, Eldepryl & 0 & no \\
\hline 7 & 45 & M & $<1$ & Eldepryl & 0 & yes \\
\hline 8 & 71 & $\mathrm{~F}$ & 5 & Sinemet, Permax & 0 & yes \\
\hline 9 & 55 & $\mathbf{M}$ & 5 & Sinemet-CR, Symmetrel, Eldepryl & 1 & yes \\
\hline 10 & 77 & $\mathrm{~F}$ & 3 & Prolopa & 0 & - \\
\hline
\end{tabular}

X \pm S.D. $66 \pm 10 \quad 7 \pm 5$

$+\quad$ Based on the subject's recall

Based on a clinical test in which the experimenter administered a backward thrust to the patient's shoulder (Weiner 1989).

yes $=2$ steps backward or more; no $=0$ to 1 step backward; $-=$ not recorded

$\mathrm{M}$ male; $\mathrm{F}$ female

$X \pm$ S.D. Mean \pm standard deviation 
counteracting the enhanced postural responses, evoked by toeup rotation of the standing platform in PD patients. Furthermore, it had no effect on their lack of adaptability of postural responses to different support surface conditions, or body positions. ${ }^{4}$ Nevertheless, we still made sure that any possible effects of medication were similar among patients, by standardizing the moment of drug intake relative to the beginning of the testing session for every patient.

Subjects stood with bare feet on a spring-activated apparatus described in detail in our previous paper. ${ }^{9}$ Their head, shoulders, trunk and feet were firmly fixed to the tilting structure of the tilting apparatus by means of straps and canvas. To minimize possible changes in the tonic neck influences acting on the lower limb muscles, ${ }^{14,15}$ their neck was maintained in a neutral position by an adjustable neck brace. They were blindfolded to eliminate visual cues, which are known to interact with vestibular and somatosensory inputs in the control of posture and balance. ${ }^{16}$ Constant background music was provided to them through earphones, to prevent possible acoustic startle reactions being evoked at the onset of the tilt, and to ensure that any audio-spinal influence were similar among subjects. ${ }^{17}$

Tilting stimulation At an unexpected moment, subjects underwent sudden forward whole head-and-body tilts around an axis of rotation co-linear with the ankle joints. The maximum excursion was $20^{\circ}$ from the vertical, with a peak amplitude of linear head acceleration at $0.7 \mathrm{~g}( \pm 15 \%)$. The back support and the standing platform of the tilting structure were mechanically fixed at an angle of $90^{\circ}$ relative to each other. This L-shaped structure tilted as a whole to prevent ankle movement. Note that the magnitude of whole head-and-body tilts used in this study corresponds to a solid push of the subject's shoulders from behind.

$\boldsymbol{H}$-reflex stimulation $\mathrm{H}$-reflexes in the right $\mathrm{SO}$ muscle were elicited with $1 \mathrm{~ms}$ electrical pulses delivered to the right posterior tibial nerve via a cathode (Medi-Trace ECE-1801 skin electrode), positioned under pressure in the popliteal fossa. The anode, a silver plate, was strapped to the front of the right lower thigh. The electrical stimulation was delivered by a Grass S88 stimulator connected to a Grass SIU5 stimulus isolation unit and a Grass CCUI constant current unit. The intensity of the stimulus was adjusted to evoke H-reflexes of about $30 \%$ to $50 \%$ of the maximum $M$ response, to better reveal facilitatory or inhibitory effects. ${ }^{18.19}$ The corresponding $M$ response was kept as low as possible to minimize any antidromic effects.

During a series of 50 whole head-and-body tilts, 40 H-reflexes were sampled between 30 and $190 \mathrm{~ms}$ after the onset of head acceleration. Only $1 \mathrm{H}$-reflex was evoked per tilt. Ten tilts without electrical stimulation (Tilt ${ }_{\text {alone }}$ ) were applied at random during the series of tilts with electrical stimulation (see below), all tilts being separated by at least $5 \mathrm{sec}$ intervals. The moment of $\mathrm{H}$ reflex stimulation relative to head acceleration onset was randomized. Sets of H-reflexes were elicited during quiet standing before $\left(\mathrm{H}_{\text {pre }} ; \mathrm{n}=8-10\right.$, i.e., control situation $)$, in the middle $\left(\mathrm{H}_{\text {mid }}\right.$; $n=3-8)$, and after the series of tilts $\left(H_{\text {post }} ; n=8-10\right)$. Approximately mid-way in the experimental series of tilts $\left(\mathrm{H}_{\text {mid }}\right)$, subjects sat down and rested for approximately 15 minutes.

Trials were accepted only if the following conditions were met: (i) The amplitude of $M$ responses during tilts was within \pm $15 \%$ of the control $\mathrm{M}$ value, or $\pm 0.4 \mathrm{mV}$ when the latter was less than $1.4 \mathrm{mV}$. This approach ensured that both the stimulat- ing and recording conditions were reasonably constant from trial to trial. (ii) The mean $\mathrm{H}_{\text {post }}$ control amplitude was within $20 \%$ of $\mathrm{H}_{\mathrm{pre}}$ and/or $\mathrm{H}_{\text {mid }}$ control values, to ensure minimal changes in the general excitability of the nervous system during the experiment. (iii) The level of background EMG activity in the SO muscle was constant and remained as low as possible, to minimize changes in the pre-existing motoneuronal excitability. ${ }^{20}$ (iv) The ankle angular displacement in the $200 \mathrm{~ms}$ preceding the electrical stimulation did not exceed $3^{\circ}$. (v) Finally, the background activity in the right and left SO, TA, biceps femoris (BF) and vastus lateralis (VL) muscles was kept as low as possible and displayed minimal changes between trials. To achieve this, subjects were instructed to relax the muscles as much as possible. The EMG signal from the right SO muscle was monitored and the tilts were triggered when the signal was maintained at a low amplitude. In the few trials in which the tilt was triggered when the level of EMG was unexpectedly increased, they were rejected during the off-line analysis. H-reflex was not recorded in PD patient \#9 because no H-reflex could be elicited. In PD patient $\# 10$, control $\mathrm{H}$-reflexes varied by more than $20 \%$ and were therefore discarded.

\section{Data Collection and Analysis}

Recordings The acceleration directed at the head was recorded with a linear accelerometer (ICSensor 3021-005-P) mounted on a dental bite bar individually made for each subject. This signal was amplified (gain $=500$ ) with a custom made unit. Angular displacement of the right ankle joint in the sagittal plane was recorded with a potentiometer mounted co-axial to the subject's right ankle joint. Raw EMG signals for the H-reflex of the right SO were recorded with a pair of skin electrodes (Medi-Trace), amplified (gain $=1,000)$ and band-pass-filtered $(10-500 \mathrm{~Hz}$ ) with a DISA $15 \mathrm{CO} 1$ EMG amplifier. The ground electrode was placed on the middle of the right tibia. Raw EMG signals from the other muscles, i.e., the left SO, and the right and left TA, BF and VL, were recorded with bipolar skin electrodes (Neuromuscular Research Center Myoelectric Surface Electrode). These signals were preamplified (gain $=10$ ), amplified (gain $=100$ ) and bandpass filtered $(20-1,400 \mathrm{~Hz})$ with the Neuromuscular Research Center Isolated 8 Channel Myoelectric Amplifier. A common ground electrode was located on the left tibia.

Data acquisition The linear head acceleration, ankle angular displacement and EMG signals from 8 muscles recorded in a total of 10 channels were sampled at a rate of $4 \mathrm{KHz}$ by the analog-to-digital convertors of an EVEREX-486 computer. Data acquisition and on-line data analysis were done with the use of a computer program developed from the LabWindows library. Data acquisition lasted $500 \mathrm{~ms}$ for each trial, with a period of $100 \mathrm{~ms}$ before and $400 \mathrm{~ms}$ after tilt trigger.

Data analysis Our computer program provided on-line computation of the latency and peak-to-peak amplitude of the $\mathrm{M}$ response and H-reflex, as well as the onset and peak amplitude of linear head acceleration and ankle angular displacement. Latency values were obtained by determining the moment when the EMG amplitude of SO exceeded 2 standard deviations (S.D.) of the baseline value computed over a $50 \mathrm{~ms}$ period. Onset values were determined as the moment the acceleration or angular displacement signal exceeded 5 S.D. of its respective baseline value over a $30 \mathrm{~ms}$ duration. The level of background contraction in the SO muscle was calculated as the average of the rectified EMG signal 
during the first $50 \mathrm{~ms}$ of data acquisition, which occurred before the onset of tilt. Further data analysis involved calculating, for each subject and each trial, the time at which the electrical stimulation was delivered relative to the acceleration onset, defined as "the inter-stimulus interval". Amplitude of $\mathrm{M}$ responses and $\mathrm{H}$ reflexes obtained during tilts were normalized as a percentage of the corresponding mean control values obtained during quiet standing. For each subject, the average of these normalized values was calculated over 4 inter-stimulus interval bins of $40 \mathrm{~ms}$, i.e., $30-70 \mathrm{~ms}, 71-110 \mathrm{~ms}, 111-150 \mathrm{~ms}$ and $151-190 \mathrm{~ms}$. In 1 PD patient, the normalized value of $\mathrm{H}$-reflex at $151-190 \mathrm{~ms}$ after head acceleration onset increased by up to $575 \%$ of control $\mathrm{H}$. To avoid undue skewing of the group mean value, this outlying variable was excluded from calculation.

The signals from each trial were inspected visually. For Tilt $_{\text {alone }}$ trials, EMG signals were rectified. Those with evidence of amplitude changes relative to the baseline were kept for averaging. An average signal was calculated only if a response was present in at least $30 \%$ of the trials. This was done to avoid possible randomly-occurring responses being analyzed as real tiltevoked responses. The onset and offset of the averaged tilt-evoked responses were defined as the moment the signal exceeded or returned to 2 standard deviations above the baseline. The EMG area located between the response onset and offset was calculated with the use of Matlab software.

Statistical analysis A two-way ANOVA for repeated measures was used to detect significant effects of subject's group on the amplitude of H-reflex during whole head-and-body tilts. Tukey's test (post-hoc) localized the possible difference. The Student "t" test was used for the analysis of individual head acceleration and electrical stimulation parameters. Chi square and Fisher's exact tests were chosen to analyze ratio values. When dependent variables were averaged within subjects, nonparametric Mann-Whitney tests were used to detect betweengroup differences.

\section{RESULTS}

\section{Similarity of Head Acceleration and H-reflex Parameters} Between Subject Groups

Table 2 summarizes the group average values obtained for head acceleration and H-reflex. As mentioned in the Methods section, the peak of linear head acceleration was kept at $0.7 \mathrm{~g} \pm$ $0.1 \mathrm{~g}$ for each subject and each trial. Table 2 shows that the mean of peak acceleration was within this range for the age-matched normal subjects and PD patients. The mean amplitude of control $M$ response was also similar between the 2 subject groups $(p>0.05)$. This finding suggested that any antidromic effect

Table 2: Comparison of Head Acceleration and H-reflex Between Normal Elderly Subjects and PD Patients.

\begin{tabular}{|c|c|c|c|}
\hline & Normal Elderly & PD Patients & \\
\hline \multicolumn{4}{|c|}{ Linear Head Acceleration } \\
\hline Peak acceleration $(\mathrm{g})$ & $.73 \pm \quad .02$ & $.69 \pm .03$ & \\
\hline \multicolumn{4}{|l|}{ H-reflex } \\
\hline Control $\mathbf{M}\left(\%\right.$ of $\left.\mathrm{M}_{\max }\right)$ & $17.1 \pm 8.8$ & $22.2 \pm 16.4$ & n.s. \\
\hline Control $\mathrm{H}\left(\%\right.$ of $\left.\mathrm{M}_{\max }\right)$ & $35.5 \pm 12.7$ & $36.6 \pm 17.7$ & n.s. \\
\hline
\end{tabular}

evoked by the electrical stimulation of the posterior tibial nerve was approximately equal across subjects. The mean control $\mathrm{H}$ reflex was also similar between subject groups ( $p>0.05$ ), indicating that the H-reflex excitability did not differ across subjects during quiet standing.

\section{EMG Responses Evoked by Whole Head-and-Body Tilts}

All patients with PD (10/10) and 78\% (7/9) of control subjects manifested muscle responses in their lower limb to Tilt $_{\text {alone }}$. Figure 1 illustrates representative examples of tiltevoked responses obtained at less than $130 \mathrm{~ms}$ after the tilt onset in a PD patient (\#1) and a normal subject of similar age (\#8). Note the much larger responses especially in the SO muscle of the PD patient, despite similar background contractions (Figure 1, 1st EMG traces). Indeed, patients with PD were more responsive to Tilt $t_{\text {alone }}$ than control subjects. This was shown by the significantly larger frequency of their response occurrence $(p<0.05)$, i.e., $62 \%$ of trials when all the muscles were grouped, in comparison with $28 \%$ of trials in similarly aged normal subjects. Interestingly, the larger occurrence of tilt-evoked responses observed in PD patients was not entirely uniform across the 4 muscles recorded. Figure 2 shows that a significantly larger proportion of $\mathrm{PD}$ patients demonstrated responses in the SO, BF and VL muscles than age-matched normal subjects $(p<0.05)$, but not in the TA muscle. This occurred despite a similarly low level of background contraction (see data in the first 2 columns of Table 3). Furthermore, the EMG response area in the SO muscle was significantly larger ( $p<0.01)$, by $413 \%$ in comparison with similarly aged normal subjects (see the last 3 columns in Table 3 ).

In general, muscle responses of PD patients tended to occur with shorter latencies than in age-matched normal subjects. For example, $52 \%$ of all response latencies obtained in PD patients were within $100 \mathrm{~ms}$, in comparison with only $33 \%$ in agematched normal subjects. In fact, the mean response latency in the TA muscle of PD patients was significantly shorter than in agematched normal subjects $(p<0.05$, Table 3$)$. Another difference between subject groups appeared to be the temporal pattern of muscle activation. Table 3 ( 3 rd and 4th columns) shows that averaged response latencies in the SO, BF and VL muscles of PD patients were approximately simultaneous at $100-111 \mathrm{~ms}$ after head acceleration onset. In contrast, muscles of similarly aged normal subjects responded with their averaged latencies separated by 16 to $44 \mathrm{~ms}$ across muscles. The sequence of muscle activation recruitment was from posterior-to-anterior compartment (SO-BF before TA-VL), and from distal-to-proximal groups (SO before $\mathrm{BF}$, and $\mathrm{TA}$ before $\mathrm{VL}$ ) in normal subjects. In patients with $\mathrm{PD}$, these sequences were disrupted by the earlier activation of the VL muscle before TA and BF (see 3rd and 4th columns in Table 3).

\section{Modulation of Soleus H-reflex During Whole Head-and- Body Tilts}

Figure $3 \mathrm{~A}$ illustrates 2 representative examples of significant SO H-reflex facilitation during whole head-and-body tilts in 1 patient with PD (\#2) and 1 normal subject of similar age (\#8). The average latencies of $M$ responses and $\mathrm{H}$-reflexes were similar between the 2 subjects, i.e., 6 and $34 \mathrm{~ms}$ for PD patient \#2, and 8 and $34 \mathrm{~ms}$ for normal subject \#8. Figure 3B shows individual $M$ responses and $H$-reflex amplitudes obtained during quiet standing, and during tilt between 40 and $210 \mathrm{~ms}$ after head acceleration onset in these 2 subjects. 


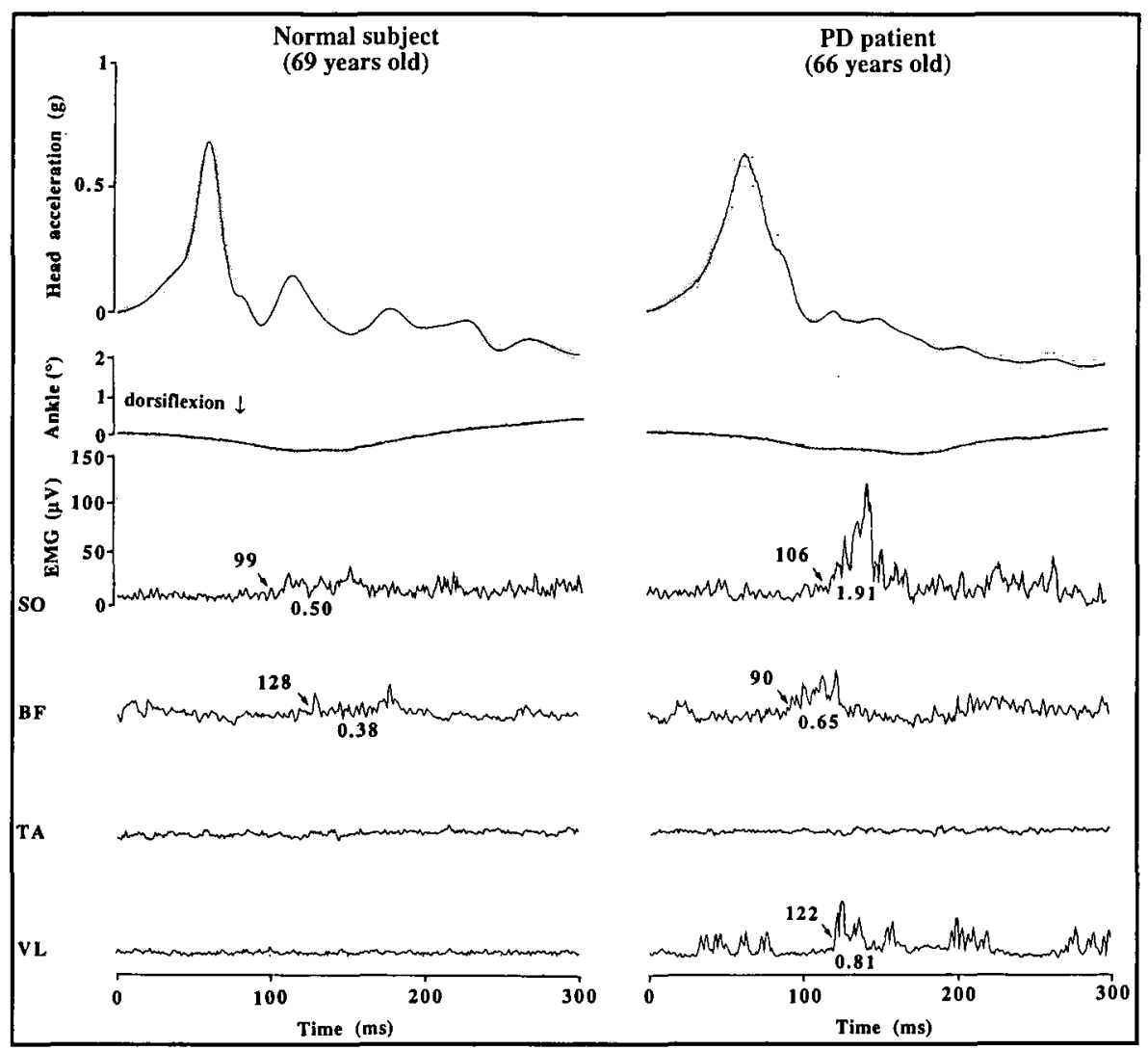

Figure 1: Mean linear head acceleration ( \pm 1 S.D. in dotted line), mean ankle angle and mean EMG traces obtained during the Tilt ${ }_{a l o n e}$ condition in normal subject \#8 and PD patient \#1. Latencies (in ms) of tilt-evoked responses are indicated by the number above each arrow. EMG areas (in $\mu V^{*}$ s) are specified by the value in the bottom of traces.

In a majority of subjects, the SO H-reflex amplitude was significantly changed during tilt, i.e., in 6 of $8(75 \%)$ PD patients and 6 of $10(60 \%)$ age-matched normal subjects. However, this modulation was either an increase or a decrease in the H-reflex amplitude. Figure 4 shows that SO H-reflex was significantly increased during tilt in 6 of $8(75 \%)$ PD patients and 5 of $10(50 \%)$ agematched normal subjects. The proportion of PD patients and agematched normal subjects showing an increase, a decrease or no effect on $\mathrm{H}$-reflex amplitude was not significantly different.

As shown by Table 4, the mean H-reflex value obtained in PD patients at 30-70 ms after head acceleration onset was significantly larger by $14 \%(\mathrm{p}<0.05)$, in comparison with agematched normal subjects. In contrast, the mean $\mathrm{H}$-reflex values between 71 and $190 \mathrm{~ms}$ after head acceleration onset were not statistically different between the 2 groups of subjects.

\section{Discussion}

In this study, we found that the responsiveness of PD patients to whole head-and-body tilts was increased in comparison with age-matched normal subjects. This was shown by the larger proportion of PD patients manifesting tilt-evoked responses in the SO, BF and VL muscles ( $p<0.05$, Figure 2$)$, and the higher frequency of their response occurrence $(p<0.05)$. Furthermore, the mean response latency in the TA muscle of PD patients was shorter $(\mathrm{p}<0.05$, Table 3$)$, and their mean SO response area larger than age-matched normal subjects $(413 \%$; $\mathrm{p}<0.01$, Table 3$)$.
PD patients were also characterized by an abnormal sequence of muscle activation in response to tilt, with their VL muscle being activated first rather than last (Table 3). Interestingly, while the mean SO response area of PD patients was greatly enhanced, their SO H-reflex amplitude during tilt was increased by only $14 \%$ at $30-70 \mathrm{~ms}$ after head acceleration onset $(\mathrm{p}<0.05$, Table 4$)$. In all but $1 \mathrm{PD}$ patient, this increased $\mathrm{H}$-reflex amplitude occurred after the onset of the SO tilt-evoked response.

\section{Increased Responsiveness and Abnormal Response Patterns to Whole Head-and-Body Tilts in PD Patients}

PD patients were more responsive to dynamic forward whole head-and-body tilts than aged-matched normal subjects. Such tilts probably provide predominant, but not exclusive vestibular inputs. Cutaneous inputs from every body part that was in contact with the tilting apparatus, and proprioceptive inputs from minimized joint displacements were present. Thus, vestibular and somatosensory inputs were provided during whole headand-body tilts.

The proportion of respondents in the SO, BF and VL muscles of PD patients was significantly increased, respectively by $1.8,3.4$ and 4.0 times than of age-matched normals $(\mathrm{p}<0.05$, Figure 2). Moreover, the responding PD patients manifested tilt-evoked responses significantly more frequently, i.e., 2.2 times more muscles-trials than normal subjects $(\mathrm{p}<0.05)$. The mean response latency in their TA muscle was shorter by 45 $\mathrm{ms}(\mathrm{p}<0.05$, Table 3 ), while the mean responses area in their 


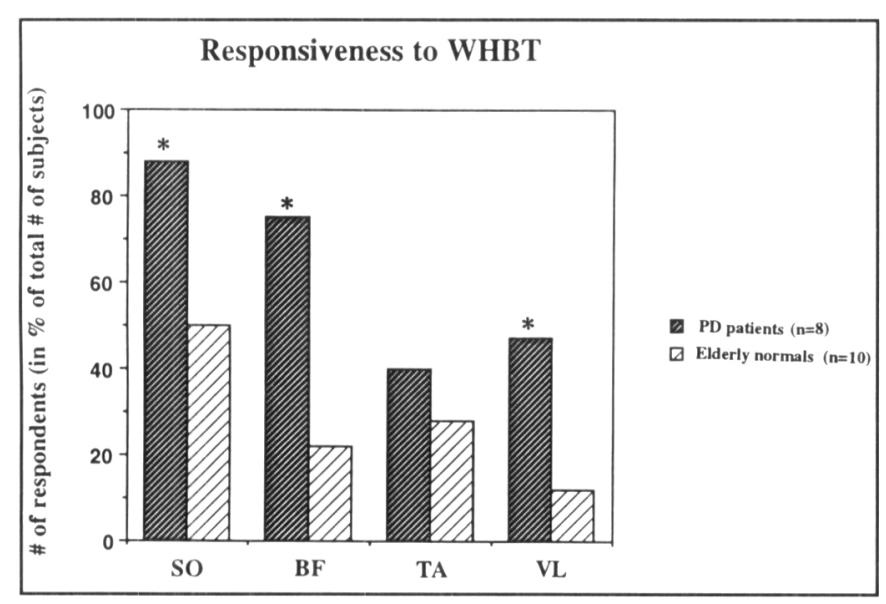

Figure 2: Proportion of $P D$ patients and age-matched normal subjects manifesting tilt-evoked responses in the SO, BF, TA and VL muscles. Significant difference between the two groups of subjects at $p<0.05$ is indicated by a star $(*)$.

SO muscle was larger (413\%; $p<0.01$, Table 3$)$. This enhanced responsiveness occurred despite similar levels of background contraction in the relevant muscles. These results are consistent with the fact that PD patients demonstrate enhanced postural responses to sudden translation or rotation of the standing platform. ${ }^{7,8}$ Consequently, muscle responses evoked by both slow platform displacements and fast whole head-and-body tilts were similarly affected in PD. The increased responsiveness to tilt of our PD patients could have been due to a lack of response suppression in the PD patients by a reduction in functional demand, due to the body support. In this context, the reduction of postural response amplitude by body support was found to be much less in PD patients than age-matched normal subjects, during toe-up and backward translation of the standing platform. ${ }^{8}$ In our experimental paradigm, subjects were firmly fixed to the tilting apparatus. Thus, tilt-evoked responses might have been less suppressed by body support in PD patients than in normal subjects.

Furthermore, the sequence of muscle activation evoked by whole head-and-body tilts was abnormal in PD patients. In particular, the VL responses tended to occur earlier in PD patients than in age-matched normal subjects (Table 3). We found that normal elderly subjects had a distinct distal-to-proximal sequence of tiltevoked activation of their lower limb muscles (SO, BF and VL). In contrast, these muscles tended to be activated almost simultaneously between 100-111 ms in the PD patients (Table 3). The simultaneous muscle activation in PD patients suggests that whole head-and-body tilts might have provoked a "freezing phenomenon", in which lower limb muscles were co-activated. Such a non-functional response might explain the difficulty faced by PD patients to restabilize their balance following stance perturbations.

The normal SO-BF-TA-VL sequence of muscle activation evoked by whole head-and-body tilts was disrupted by the earlier activation of the VL muscle in PD patients. A reduced VL muscle response latency has also been found in PD patients during toe-up rotation of the standing platform. ${ }^{6}$ This is another example that PD affected postural and balance responses, evoked respectively by slow and fast stance perturbations, in a similar manner. With the slow perturbation, however, only patients in stage 4 of the disease manifested an abnormal muscle activation sequence, and not the patients in stage $3 . .^{6}$ This is in contrast to our finding that PD patients in stage 3 already demonstrated significant changes in the sequence of muscle activation evoked by whole head-and-body tilts. Taken together, the results from the 2 studies suggest that PD might affect the sequencing of tilt-evoked responses earlier than the postural responses to slower platform perturbations.

\section{Modulation of Soleus H-reflex During Whole Head-and- Body Tilts}

The amplitude of SO H-reflex was significantly modified during whole head-and-body tilts in the majority of normal elderly subjects and PD patients. Within each subject group, the average $\mathrm{H}$ reflex amplitude during tilt was increased by $26 \%$ in normal elderly subjects, and by $20 \%$ in PD patients as compared with quiet standing. This modest increase was due in part to the decreased $\mathrm{H}$-reflex amplitude observed in 1 normal elderly subject and 1 PD patient.

The amplitude of SO H-reflex during whole head-and-body tilts was similar between PD patients and age-matched normal subjects, at an interval of 71-190 ms after head acceleration onset. However, it was significantly larger in PD patients than normal elderly subjects in the early part of the tilt $(p<0.05$, Table 4), i.e., at 30-70 ms after head acceleration onset. This difference was observed in spite of similar stimulation conditions between the two groups of subjects. As noted earlier, the variation in the peak amplitude of linear head acceleration was limited to $\pm 15 \%$ from trial to trial, and from subject to subject. This procedure ensured that similar intensity of vestibular stimulation was provided to all subjects. In addition, the similar control H-reflex

Table 3: Comparison of Background EMG and Ttilt-evoked Response Characteristics Between Normal Elderly Subjects and PD Patients.

\begin{tabular}{|c|c|c|c|c|c|c|c|}
\hline \multirow[b]{2}{*}{ Muscle } & \multicolumn{2}{|c|}{ Background EMG $(\mu \mathrm{V})$} & \multicolumn{2}{|c|}{ Response Latency (ms) } & \multicolumn{3}{|c|}{ EMG Area $\left(\mu V^{*} s\right)$} \\
\hline & Elderly & PD Patients & Elderly & PD Patients & Elderly & PD & PD/Eld. (\%) \\
\hline SO & $14 \pm 6$ & $22 \pm 15$ & $95 \pm 45$ & $100 \pm 27$ & $.39 \pm .25$ & $\mathbf{1 . 6 1} \pm 1.58^{* *}$ & 413 \\
\hline $\mathrm{TA}$ & $16 \pm 7$ & $15 \pm 10$ & $173 \pm 31$ & $128 \pm 43^{*}$ & $1.63 \pm 1.87$ & $.88 \pm .71$ & 54 \\
\hline VL & $7 \pm 2$ & $19 \pm 12$ & $212 \pm 7$ & $107 \pm 29$ & $.47 \pm .53$ & $1.15 \pm 1.23$ & 245 \\
\hline
\end{tabular}

* $\quad \mathrm{p}<0.05$

** $\quad \mathrm{p}<0.01$ 

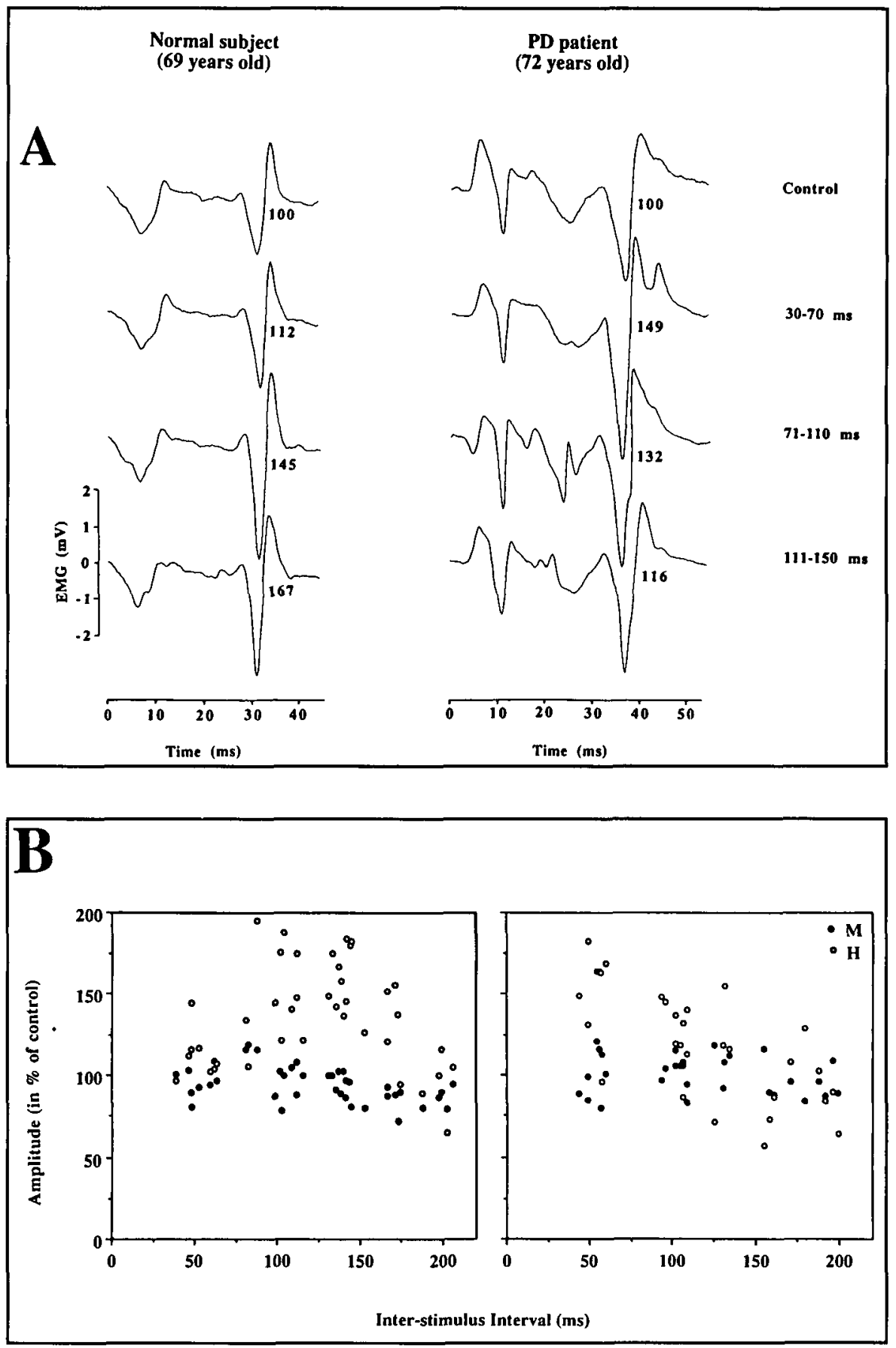

Figure 3: (A) Soleus $H$-reflexes in normal subject \#8 and PD patient \#2 during quiet standing (control), and during whole head-and-body tilts at $30-70 \mathrm{~ms}, 71.110 \mathrm{~ms}$ and $111-151 \mathrm{~ms}$ after head acceleration onset. The relative amplitude of $H$-reflex to the mean control $H$ is indicated under $H$-reflexes. (B) Individual $M$ responses (closed circles) and $H$-reflexes (open circles) obtained during whole head-and-body tilts in the same subjects, expressed in percentage of the mean control $M$ and the mean control $H$ values.

amplitude values obtained in the two subject groups (Table 2) indicated that similar proportion of motoneurons was recruited by the electrical stimulation during quiet standing.

\section{Possible Mechanism Involved in the Enhancement of Tilt- Evoked Responses With PD}

Responses evoked by whole head-and-body tilts in the SO muscle of PD patients were significantly greater than in age- matched normal subjects (Table 3). However, this enhancement was not accompanied by a comparable amount of increase in SO $\mathrm{H}$-reflex amplitude during the tilt. More specifically, the area of SO tilt-evoked responses in PD patients was larger than agematched normal subjects $(413 \%)$, while the H-reflex amplitude was increased by only $14 \%$ (Table 4 ). These results indicate that most of the increase in response area observed in PD patients could not be attributed to abnormal motoneuronal excitability 


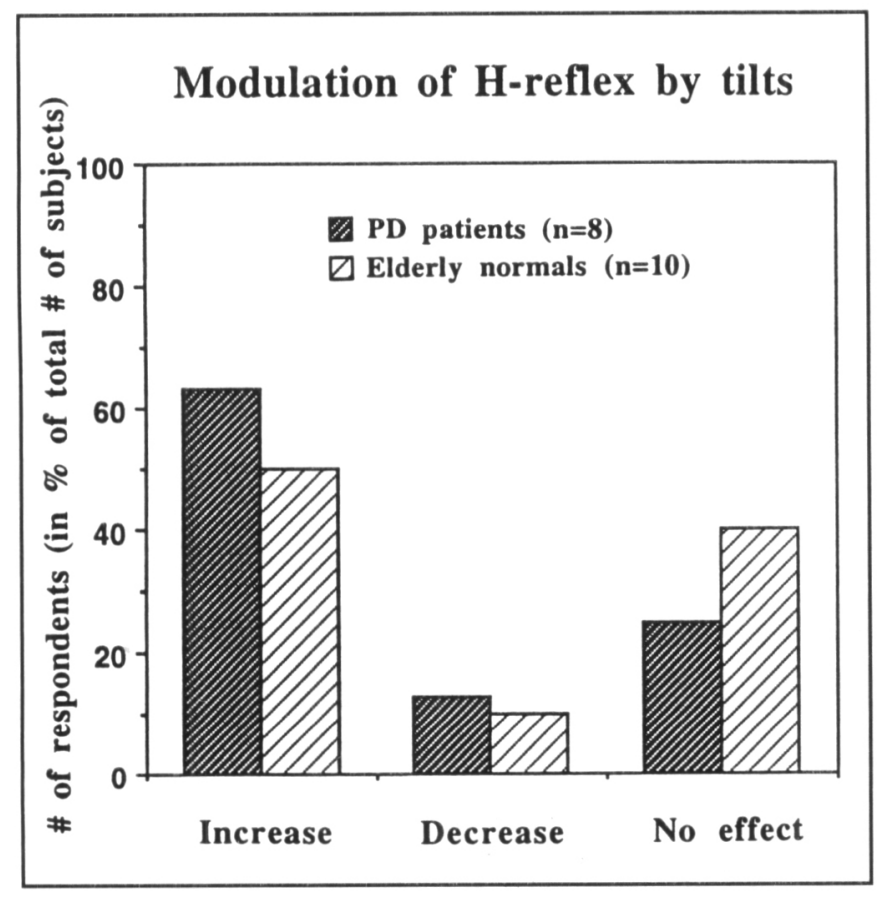

Figure 4: Relative proportion of $P D$ patients and age-matched normal subjects, in percentage of the total number of subjects in each groups, showing a significant increase, a significant decrease, or no effect in the soleus $H$-reflex amplitude during whole head-and-body tilts.

during tilt. Instead, the enlarged responses could originate from a deficit in the control of interneuronal excitability. For example, an increased facilitation and/or a decreased inhibition of the interneurons involved in the generation of tilt-evoked responses could explain our finding of a minor increase in H-reflex amplitude during tilt and a much more excitable tilt-evoked response.

In support of this hypothesis, other polysynaptic reflexes have been found to be hyperactive in PD patients. Notable examples are the medium latency stretch reflex, i.e., the M2 response, in the upper $\operatorname{limb}^{21}$ and TA muscles, 22 as well as the flexion reflex in lower limb muscles. ${ }^{23}$ In contrast, the monosynaptic stretch reflex of PD patients is normal in both upper ${ }^{24}$ and lower limb muscles. ${ }^{6}$ Therefore, the origin of parkinsonian reflex hyperactivity could be a defect in the control of the interneurons participating in these polysynaptic reflexes.

In this connection, the regulation of Renshaw, Ia and Ib inhibitory interneurons has been assessed specifically in PD patients. The inhibition of SO H-reflex by a conditioning stimulation of the posterior tibial nerve, presumed to activate Reshaw inhibitory interneurons, ${ }^{25}$ was intact in PD patients. ${ }^{26}$ In contrast, the H-reflex of PD patients was excessively inhibited by conditioning stimulation of the peroneal nerve, thought to activate the SO Ia interneurons. ${ }^{27}$ Furthermore, the H-reflex of PD patients was insufficiently inhibited by a conditioning stimulation of the gastrocnemius nerve, ${ }^{28}$ presumed to activate the SO Ib interneurons. ${ }^{29}$ These results suggested that the excitability of Ia and $\mathrm{Ib}$ inhibitory interneurons was respectively increased and decreased in PD patients. They also illustrate examples of abnormal interneuronal control in PD. Were the interneurons in the tilt-evoked response pathway being abnormally controlled in $\mathrm{PD}$, it could explain the greatly enhanced responses despite a minor increase in H-reflex amplitude that we observed during tilts in PD patients.

To sum, we have characterized the tilt-evoked responses of PD patients with the use of a new experimental paradigm, in which the subject's whole head-and-body was tilted forward. The responsiveness to whole head-and-body tilts was much greater in PD patients than age-matched normal subjects. This hyperexcitability could reflect a reduced capacity of PD patients to modulate the amplitude of tilt-evoked responses according to functional demand. More specifically, the body support used in our experimental paradigm should have reduced the tilt-evoked responses. Instead, when compared with age-matched normal subjects, the area of SO responses was 4 times larger in PD patients. During similar tilts, the SO H-reflex amplitude of PD patients was only slightly increased in comparison with normal subjects. These results indicate that possible hyperexcitability of motoneurons, and/or decreased presynaptic inhibition of the Ia terminals involved in the H-reflex pathway, could not fully account for the enhanced tilt-evoked responses of PD patients. We hypothesize that the increased responsiveness to whole head-and-body tilts in PD patients could originate from an abnormal excitability of the spinal interneurons.

\section{ACKNOWLEDGEMENTS}

This project was financed by the Parkinson's Foundation of Canada. N. Paquet was supported by a studentship from the Medical Research Council of Canada. The authors acknowledge the assistance of A. Alfath, S. Carrier, Y.K. Kim, Dr. J. Liu and F. Tam. We thank Dr. D.G. D. Watt for his advice on the experimental protocol.

\section{REFERENCES}

1. Weiner WJ. Parkinson's Disease. In: Weiner VJ, Goetz CG, eds. Neurology for the Non-Neurologist, second edition. Philadelphia: JB Lippincott, 1989: 109-117.

2. Jankovic J, McDermott M, Carter J, et al. Variable expression of Parkinson's Disease: a base-line analysis of the DATATOP cohort. Neurology 1990; 40: 1529-1534.

3. Waterston JA, Hawken MB, Tanyeri S, Jantti P, Kennard C. Influence of sensory manipulation on postural control in Parkinson's disease. J Neurol Neurosurg Psychiatry 1993; 56: 1276-1281.

4. Horak FB, Nutt JG, Nashner LM. Postural inflexibility in parkinsonian subjects. J Neurol Sci 1992; 111: 46-58

Table 4: Mean H-reflex Amplitude \pm 1 S.D. Obtained During Quiet Standing (Control) and 4 Inter-stimulus Intervals During Whole Head-and-Body Tilts.

\begin{tabular}{|c|c|c|c|c|c|c|c|c|c|c|}
\hline \multirow{2}{*}{$\begin{array}{l}\text { Group } \\
\text { Elderly normals }\end{array}$} & \multicolumn{2}{|c|}{ Control } & \multicolumn{2}{|c|}{$30-70 \mathrm{~ms}$} & \multicolumn{2}{|c|}{$71.110 \mathrm{~ms}$} & \multicolumn{2}{|c|}{$111-150 \mathrm{~ms}$} & \multicolumn{2}{|c|}{$151-190 \mathrm{~ms}$} \\
\hline & $100 \pm 0$ & $(n=10)$ & $106 \pm 37$ & $(n=10)$ & $126 \pm 43$ & $(\mathrm{n}=9)$ & $119 \pm 49$ & $(\mathrm{n}=9)$ & $121 \pm 41$ & $(n=10)$ \\
\hline PD patients & $100 \pm 0$ & $(n=8)$ & $120 \pm 30^{*}$ & $(n=6)$ & $114 \pm 30$ & $(\mathbf{n}=3)$ & $102 \pm 42$ & $(n=5)$ & $93 \pm 30$ & $(n=5)$ \\
\hline
\end{tabular}

* $\mathrm{p}<0.05$

() number of subjects 
5. Schieppati M, Hugon M, Grasso M, Nardone A, Galante M. The limits of equilibrium in young and elderly normal subjects and in parkinsonians. Electroencephal Clin Neurophysiol 1994; 93: 286-298.

6. Beckley DJ, Bloem BR, van Dijk JG, Roos RAC, Remler MP. Electrophysiological correlates of postural instability in Parkinson's disease. Electroencephal Clin Neurophysiol 1991; 81: 263-268.

7. Bloem BR, Beckley DJ, van Dijk JG, Zwinderman AH, Roos RAC. Are medium and long latency reflexes a screening tool for early Parkinson's disease? J Neurol Sci 1992; 113: 38-42.

8. Schieppati M, Nardone A. Free and supported stance in Parkinson's disease. Brain 1991; 114: 1227-1244

9. LoMonaco E, Hui-Chan CWY, Paquet N. A spring-activated tilting apparatus for the study of balance control in man. J Neurosci Methods 1995; 58: 39-48.

10. Hui-Chan CWY, LoMonaco E, Paquet N. Interaction of vestibulospinal and somatosensory inputs in the control of balance in man. Soc Neurosci Abstr 1991; 17: 1026.

11. Reichert WH, Doolittle J, McDowell FH. Vestibular dysfunction in Parkinson's Disease. Neurology 1982; 32: 1133-1138.

12. Hoehn MM, Yahr MD. Parkinsonism: onset, progression and mortality. Neurology 1967; 17: 427-442.

13. Bonnet AM, Loria Y, Saint-Hilaire MH, Lhermite F. Agid Y. Does long-term agravation of Parkinson's disease result from nondopaminergic lesions? Neurology 1987; 37: 1539-1542.

14. Traccis S, Rosati G, Patraskakis S, et al. Influence of neck receptors on soleus motoneuron excitability in man. Exp Neurol 1987; 95 : 76-84.

15. Wilson VJ, Peterson BW. Vestibulospinal and reticulospinal systems. In: Brooks VB, ed. American Physiological Society's Handbook of Physiology. Section I. The Nervous System, Vol. 2: Motor Control. Williams and Wilkins: Baltimore, 1981: 667. 702.

16. Nashner LM, Berthoz A. Visual contribution to rapid motor responses during postural control. Brain Res 1978; 150: 403407.
17. Davies M. The mammalian startle response. In: Eaton RC, ed. Neural Mechanisms of Startle Behavior. Plenum Press: New York, 1984: 287-351.

18. Crone $\mathrm{C}$, Hultborn $\mathrm{H}$, Mazières $\mathrm{L}$, et al. Sensitivity of monosynaptic test reflexes to facilitation and inhibition as a function of the test reflex size: a study in man and cat. Exp Brain Res 1990; 81: 35-45.

19. Meink HM. Facilitation and inhibition of the human $H$ reflex as a function of the amplitude of the control reflex. Electroencephalogr Clin Neurophysiol 1980; 48: 203-211.

20. Verrier MC. Alterations in H-reflex magnitude by variations in baseline EMG excitability. Electroencephalogr Clin Neurophysiol 1985; 60: 492-499.

21. Tatton WG, Lee RG. Evidence for abnormal long-loop reflexes in rigid Parkinsonian patients. Brain Res 1975; 100: 671-676.

22. Chan CWY, Kearney RE, Melvill Jones G. Tibialis anterior response to sudden ankle displacements in normal and parkinsonian subjects. Brain Res 1979; 173: 303-314.

23. Delwaide PJ, Schwab RS, Young RR. Polysynaptic spinal reflexes in Parkinson's Disease. Neurology 1974; 24: 820-827.

24. Cody FWJ, Macdermott N, Matthews PBC, Richardson HC. Observations on the genesis of the stretch reflex in Parkinson's disease. Brain 1986; 109: 229-249.

25. Katz R, Pierrot-Deseilligny E. Recurrent inhibition of alphamotoneurons in patients with upper motor lesions. Brain 1982; 105: $103-124$.

26. Delwaide PJ. Are there modifications in spinal cord functions of parkinsonian patients? In: Delwaide PJ, Agnoli A, eds. Clinical Neurophysiology in Parkinsonism. Amsterdam: Elsevier, 1985: 19-32.

27. Tanaka R. Reciprocal Ia inhibition during voluntary movements in man. Exp Brain Res 1974: 21: 529-540.

28. Delwaide PJ, Pepin JL, Maertens de Noordhout A. Short-latency autogenic inhibition in patients with parkinsonian rigidity. Ann Neurol 1991; 30: 83-89.

29. Pierrot-Deseilligny E, Morin C, Bergego C, Tankov N. Pattern of group I fibers projections from ankle flexor and extensor muscle in man. Exp Brain Res 1981; 42: 337-350. 